\title{
CALCIFYING EPITHELIAL ODONTOGENIC TUMOR: A CASE REPORT
}

\author{
Jawad Ahmad Kundi', Muhammad Ilyas ${ }^{1}$, Salman Khan ${ }^{1}$, Faryal Gul', Muhammad Umar ${ }^{1}$
}

\author{
1. Sardar Begum Dental College
}

\begin{abstract}
Calcifying epithelial odontogenic tumor (CEOT) is a rare odontogenic tumor, accounts $0.4 \%$ to $3 \%$ of all odontogenic tumors arising from odontogenic epithelium. Dr. Jens JorgenPindborg first described this unusual lesion; subsequently Shafer et al coined the term Pindborg tumor. It occurs most commonly in the $4^{\text {th }}$ to $6^{\text {th }}$ decade and bears no gender predilection. A case of CEOT in a 55 years old female extending from themesial aspect of right lower canine to the contralateral third molar region is described.
\end{abstract}

\section{KEY WORDS}

CEOT, Pindborg tumor, Hemimandibulectomy.

\section{INTRODUCTION}

Calcifying epithelial odontogenic tumor (CEOT) is a rare odontogenic tumor arising from

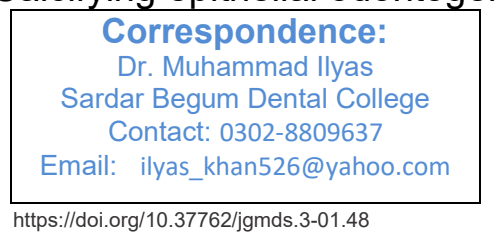
odontogenic epithelium ${ }^{1}$.It was first described by Jens Jorgen Pindborg in $1955^{2}$. Shafer et $\mathrm{al}^{3}$ give Pindborg tumor eponymously. CEOT is very uncommon and accounts $0.4 \%$ to $3 \%$ of all odontogenic tumors ${ }^{4}$. Most CEOT are seen in the forth to sixth decade of life ${ }^{5}$.CEOT is considered as benign but locally aggressive

in nature with recurrence rate of $10-15 \%{ }^{6}$ CEOT occurs as a single, painless, gingival mass resembling oral hyperplastic mucosal lesion ${ }^{7}$. Radiographically, CEOT areunilocular or multilocular radiolucent areas with patchy radio-opacity Histologically, it consists of polyhedral odontogenic epithelial cell cords, interspersed with extracellular amyloid ${ }^{4,8}$.

\section{CASE REPORT}

A 55-year-old female patient came to the Department of Oral \& Maxillofacial Surgery, Sardar Begum Dental College, Peshawar with a chief complaint of slowly progressive swelling on the left side of her lower jaw for the last 12 years. On intra-oral examination, the left lower buccal and lingual vestibule was obliterated due to the expansion of the buccal and lingual cortical plate. The lesion was seen extending from central incisor to the contralateral third molar, measuring approximately $8 \times 4 \mathrm{~cm}$ in size (Figure.1). On palpation, the swelling was slightly tender, firm, smooth and painless.

Figure \# 1: Intra-oral aspect of the lesion characterized by firm, smooth swelling obliterating buccal and lingual vestibule on the left side of the mandible. 
Orthopantomograph revealed a mixed radiolucent-radiopaque lesion, which was multilocular with coarse trabeculae and scattered foci of calcification extending from the mesial aspect of right lower canine to the contralateral third molar region and measuring approximately $9 \times 4 \mathrm{~cm}$ in size (Figure.2). Inferiorly, the lesion was extending till the lower mandibular margin and there is discontinuity in the lower border of mandible.

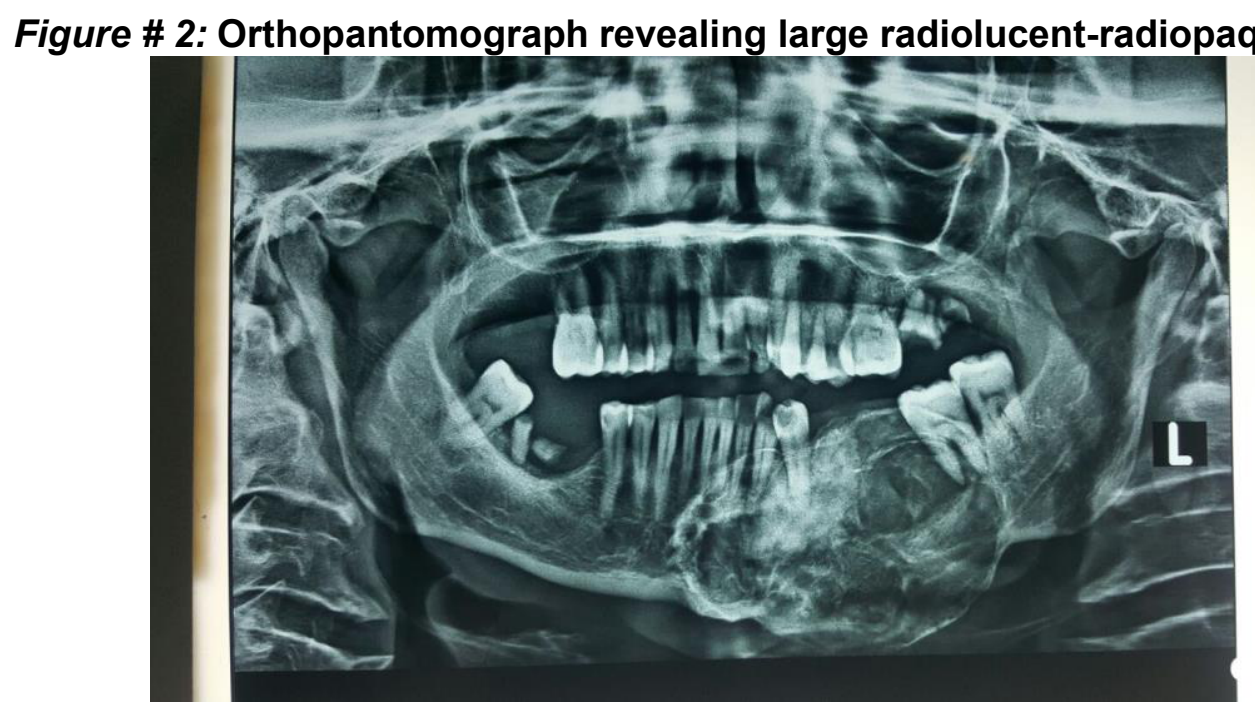

An incisional biopsy of $0.5 \mathrm{~cm} \times 0.2 \mathrm{~cm} \times 0.1 \mathrm{~cm}$ from the region involved was sent for histopathological examination. Sections showed sheets and polyhedral eosinophilic squamous epithelial cells, pleomorphic cells with 2-3 nuclei and few amyloid bodies, diagnosing the lesion to be CEOT. In view of the extensive involvement, resection of the involved portion of the mandible and reconstruction with a reconstruction plate was planned. The mandible was exposed via an extraoral approach through lip split technique and resection of the left hemimandible from right canine to the left third molar with safe clinical margins was performed (Figure.3 and 4) and defect was bridged with reconstruction plate (Figure.5). The resected specimen was measuring $9.5 \times 4.5 \times 5 \mathrm{~cm}$ (Figure.6).

Figure \# 3: Exposing the lesion through extra-oral lip split technique.

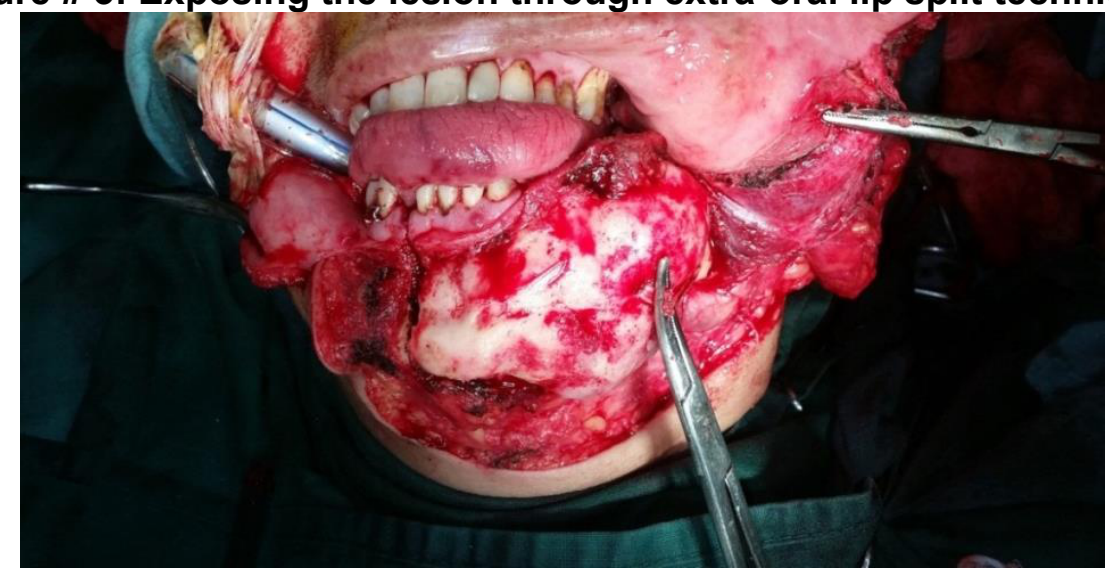


Figure \# 4: Resection of the left hemimandible from the right canine to contralateral third molar with safe clinical margins.

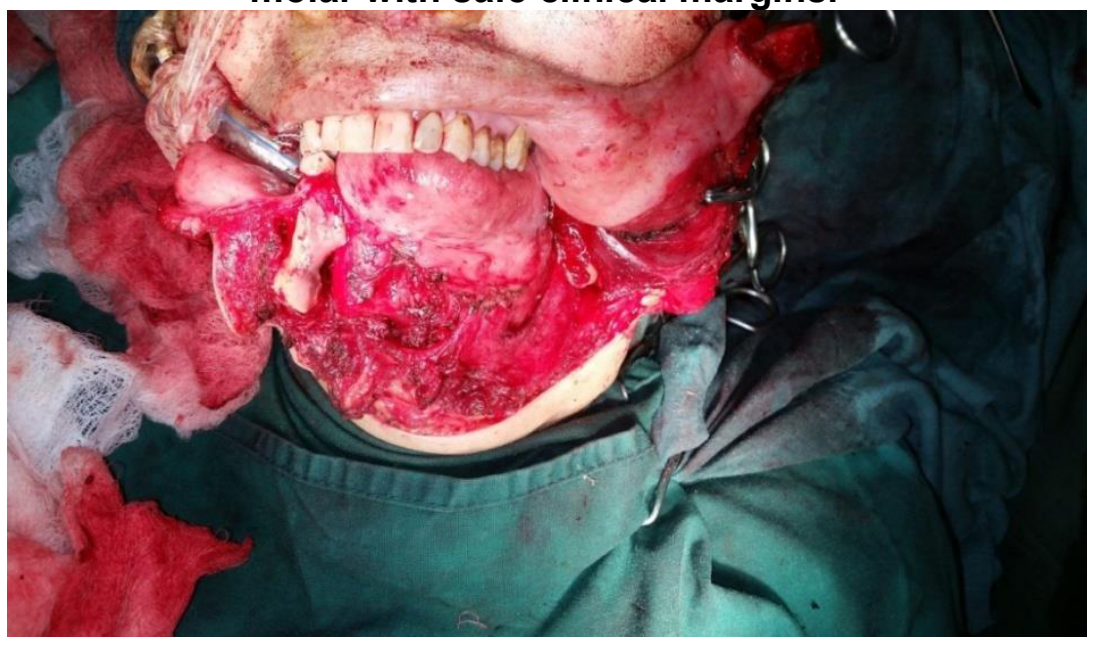

Figure \# 5: The defect was bridged with reconstruction plate.

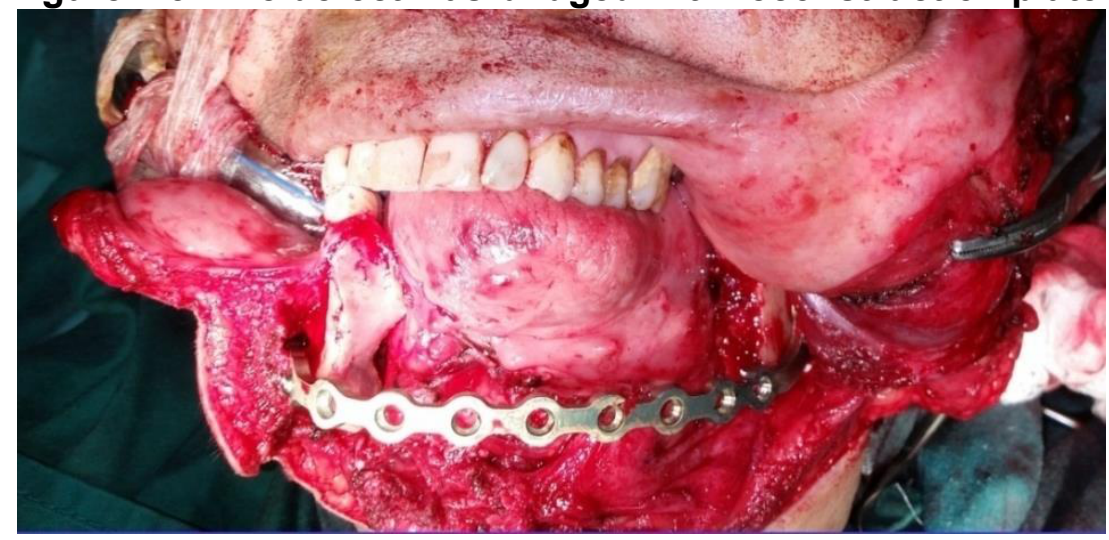

Figure \# 6: The resected specimen measuring $9.5^{\star} 4.5^{\star} 5 \mathrm{~cm}$.

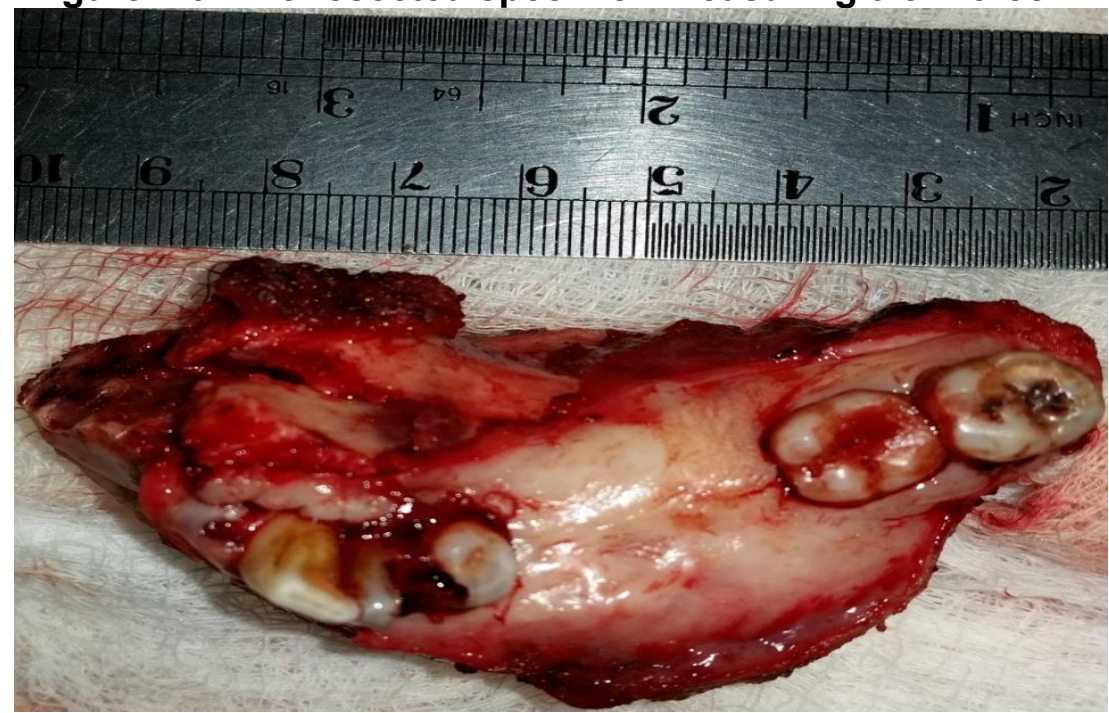




\section{DISCUSSION}

CEOT is a rare benign but locally aggressive tumor and the lesion is a distinct entity and probably represents less than $1 \%$ of all odontogenic tumors. The CEOT is more common between $3^{\text {rd }}$ and $6^{\text {th }}$ decade of life ${ }^{3}$ which support the present case. There is no gender predilection. About half of the cases of CEOT are associated with an impacted tooth, usually with a mandibular molar tooth $^{9}$. The tumor grows slowly by infiltration, painless and producing cortical expansion as seen in the case reported.The radiographic appearance of CEOT is variable and depends on the stage of development. It ranges from unilocular, pericoronal, radiolucency, pericoronal radiolucency with irregular calcific flecks, mixed radiopaque-radiolucent lesion, driven-snow appearance to an entirely radiopaque mass ${ }^{10}$. Histopathologic feature usually show islands and strands of polyhedral epithelial cells with nuclear pleomorphism, prominent nucleoli and intercellular bridges ${ }^{4,5}$ One of the characteristic microscopic features of this tumor is the presence of amorphous, eosinophillichyalinized and acellular areas resembling amyloid within or adjacent to epithelial islands ${ }^{4,11}$.These epithelial islands and amyloid-like materials were seen in our case also. Numerous treatment modalities have been suggested and the treatment plan is dependent size and location of lesion, general condition of patient and operator skill. Large tumors require aggressive approach by segmental resection, hemimandibulectomy and hemimaxillectomy, which cause bone discontinuity requiring reconstruction procedures ${ }^{4,12}$. Recurrence rate of $10-20 \%$ following conservative treatment is reported ${ }^{13}$.

\section{CONCLUSION}

CEOTs are uncommon odontogenic tumors. Being a locally aggressive tumor, resection with adequate normal margins is mandatory when treating large lesions to prevent its recurrence. Proper reconstruction of the bony defect and subsequent follow-ups are required to decrease the morbidity associated with large tumors.

\section{REFERENCES}

1. Shear M. 3rd ed. Copenhagen, Denmark: Mervyn Shear: Blackwell Munksgaard; 1992. Calcifying Odontogenic Cysts, Cysts of the Oral Regions; 102-10.

2. Pindborg JJ. A calcifying epithelial odontogenic tumor. Cancer. 1958;11:838-43.

3. Rajendran R. Cysts and tumors of odontogenic origin. In: Rajendran R, Sivapathasundharam B, editors. Shafer's Textbook of Oral Pathology. 6th ed. New Delhi: Elsevier; 2009. 278-81.

4. Philipsen HP, ReichartPA.Calcifying epithelial odontogenic tumor: Biological profile based on 181 cases from the literature. Oral Oncol. 2000;36:17-26.

5. Franklin CD, Pindborg JJ. The calcifying epithelial odontogenic tumor. A review and analysis of 113 cases. Oral Surg Oral Med Oral Pathol. 1976;42:753-65.

6. Pindborg JJ. Calcifying odontogenic tumor. Review of the literature and report of an extra-osseous case. ActaOdontolgiaScandinava. 1966; 24:419.

7. Takata TS, Slootweg PJ. Calcifying epithelial odontogenic tumor. In: Barnes LE, Eveson JW, Reichart $P$, Sidransky D, editors. Pathology and Genetics of Head and Neck Tumors. $1^{\text {st }}$ ed. Lyon: WHO IARC Press; 2005. 302-3.

8. Takeda Y, Suzuki A, Sekiyama S. Peripheral calcifying epithelial odontogenic tumor. Oral Surg Oral Med Oral Pathol 1983;56:71-5.

9. Reichart PA, Philipsen HP. Calcifying epithelial odontogenic tumors. In: Reichart PA, Philipsen HP, editors. Odontogenic Tumors and Allied Lesions. London: Quintessence Publishing; 2004.93-104. 
10. Kaplan I, Buchner L, Calderon S, Kafe I. Radiological and clinical features of calcifying epithelial odontogenic tumour. DentomaxillofacRadiol. 2001;30:22-8.

11. Mori M, Makino M. Calcifying epithelial odontogenic tumor: histochemical properties of homogeneous acellular substances in The tumor. J Oral Surg.1977;35:631-9.

12. Bouckaert MM, Roubenheimer EJ, Jacobs FJ. Calcifying epithelial odontogenic tumor with intracranial extension: Report of a case and review of literature. Oral Surg Oral Med Oral Pathol Oral RadiolEndod. 2000;90:656-62.

13. Cicconetti A, Tallarico M, Bartoli A, Ripari A, Maggiani F. Calcifying epithelial odontogenic tumor (Pindborg) tumor: A clinical case. Minerva Stomatol. 2004;53:379-87.

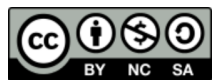

LICENSE: JGMDS publishes its articles under a Creative Commons Attribution Non-Commercial Share-Alike license (CC-BY-NC-SA 4.0) COPYRIGHTS: Authors retain the rights without any restrictions to freely download, print, share and disseminate the article for any lawful purpose. It includes scholarly networks such as Research Gate, Google Scholar, LinkedIn, Academia.edu, Twitter, and other academic or professional networking sites. 